\title{
Hyperphosphatemia in an 11-year-old girl with acute myeloid leukemia: Questions
}

\author{
Monique Albersen ${ }^{1}$ (D) $\cdot$ Arend Bökenkamp ${ }^{2} \cdot$ Hans Schotman $^{1} \cdot$ Stephanie Smetsers ${ }^{3,4}$
}

Received: 6 September 2018 / Accepted: 21 September 2018 / Published online: 5 October 2018

(C) The Author(s) 2018

\section{Case presentation}

An 11-year-old girl, recently diagnosed with acute myeloid leukemia, was treated according to the NOPHO DBH AML 2012 protocol [1]. After the third chemotherapy course, consisting of cytarabine, mitoxantrone, and intrathecal methotrexate, she was admitted to the Department of Pediatric Oncology because of septic shock during febrile neutropenia. She was treated with meropenem and vancomycin and blood cultures were positive for Streptococcus mitis. Because of persistent fever, the central venous catheter was removed. Nevertheless, the fever persisted and a chest CT was performed, which revealed multiple abnormalities suggestive of pulmonary aspergillosis, which was confirmed by bronchoalveolar lavage (BAL). On day 5 of admission, she was started on AmBisome ${ }^{\circledR}$ (liposomal amphotericin B; $5 \mathrm{mg} / \mathrm{kg}$ in glucose $5 \%$ ). Because of her persisting neutropenia, granulocyte colony-stimulating factor (G-CSF) was administered. Fever disappeared with neutrophil recovery, approximately 5 days after the start of G-CSF and AmBisome ${ }^{\circledR}$.

Repeated blood tests showed normal renal function (creatinine $35 \mu \mathrm{mol} / \mathrm{L}$, urea $3.7 \mathrm{mmol} / \mathrm{L}$ ). Potassium supplementation was started because of hypokalemia. While phosphate concentrations

The answer to this question can be found at https://doi.org/10.1007/ s00467-018-4101-5.

Monique Albersen

m.albersen@vumc.nl

1 Amsterdam UMC, Department of Clinical Chemistry, Vrije Universiteit Amsterdam, De Boelelaan 1117, 1081

HV Amsterdam, The Netherlands

2 Amsterdam UMC, Department of Pediatric Nephrology, Vrije Universiteit Amsterdam, De Boelelaan 1117, 1081

HV Amsterdam, The Netherlands

3 Amsterdam UMC, Department of Pediatric Oncology, Vrije Universiteit Amsterdam, De Boelelaan 1117, 1081 HV Amsterdam, The Netherlands

4 Prinses Máxima Centrum voor Kinderoncologie, Heidelberglaan 25, 3584 CS Utrecht, The Netherlands

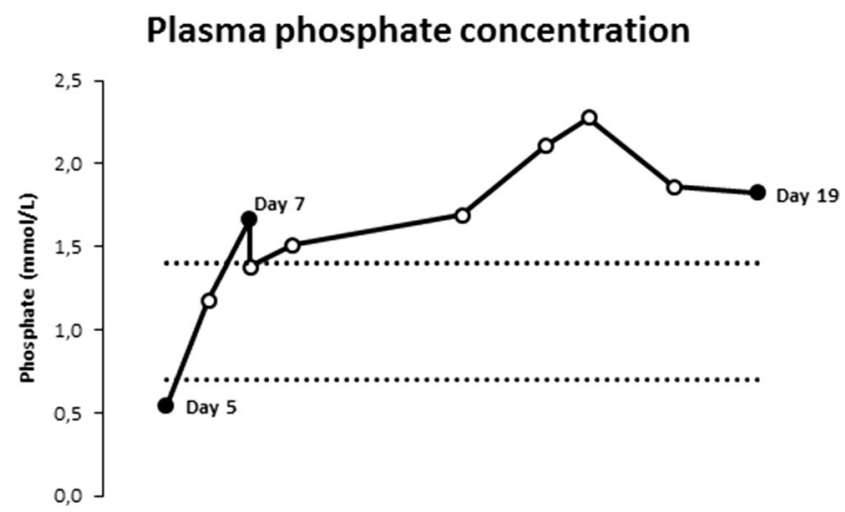

Fig. 1 Course of phosphate concentrations. The dotted lines represent the reference range $(0.70-1.40 \mathrm{mmol} / \mathrm{L})$

were low at $0.54 \mathrm{mmol} / \mathrm{L}$ on day 5 , they rose spontaneously and from day 7 onwards laboratory tests showed progressive hyperphosphatemia, with a maximum of $2.28 \mathrm{mmol} / \mathrm{L}$ (Fig. 1).

\section{Question}

What is the most likely cause of the hyperphosphatemia observed in this patient?

\section{Compliance with ethical standards}

Conflict of interest The authors declare that they have no conflict of interest.

Open Access This article is distributed under the terms of the Creative Commons Attribution 4.0 International License (http:// creativecommons.org/licenses/by/4.0/), which permits unrestricted use, distribution, and reproduction in any medium, provided you give appropriate credit to the original author(s) and the source, provide a link to the Creative Commons license, and indicate if changes were made.

\section{References}

1. NOPHO-DBH AML (2012) Protocol: research study for treatment of children and adolescents with acute myeloid leukaemia 0-18 years. EudraCT Number 2012-002934-35 (https://www. clinicaltrialsregister.eu/ctr-search/search?query=nopho+dbh+aml) 